\title{
Self-efficacy and job search success for new graduates
}

\section{Gerardo Petruzziello, Marco Giovanni Mariani and Rita Chiesa Department of Psychology, University of Bologna, Bologna, Italy, and Dina Guglielmi Department of Education Studies, University of Bologna, Bologna, Italy}

\begin{abstract}
Purpose - The purpose of this paper is to explore the relationship between general self-efficacy (GSE), job search self-efficacy (JSSE), extraversion and job search success within a sample of new entrants in the labour market. It is hypothesised that JSSE acts as a mediator between GSE and job search success. Evaluation of the hireability - made by expert interviewers - of new entrants involved in a job interview simulation is proposed as a job search success criterion. Moreover, the moderating role of extraversion on the relationship between JSSE and job search success is explored.

Design/methodology/approach - Data were collected on 177 graduates from an Italian university. Participants were involved in a simulation of an interview conducted by experts of the personnel selection process, who gave an evaluation. Macro PROCESS for SPSS was used to test the hypotheses.

Findings - GSE has an indirect effect on job search success via JSSE. Moreover, extraversion has a moderating effect on the JSSE-job search success relationship for more extraverted job seekers.

Practical implications - Job search and counselling practitioners should consider extraversion and personal differences to improve the effectiveness of interventions aimed at fostering new entrants' self-regulatory resources and behaviours during the job search.

Originality/value - This study contributes to the existing research about the job search process by testing a new and important job search success criterion, showing that GSE could help new graduates in establishing a specific self-efficacy, such as JSSE, and demonstrating that extraversion interacts with JSSE.
\end{abstract}

Keywords Job search self-efficacy, Job search success, General self-efficacy, Extraversion

Paper type Research paper

\section{Introduction}

In the past decade, multiple changes have brought new challenges to the career paths of workers as a result of the uncertainty and instability associated with labour market conditions. Hence, as outlined by De Vos and Van der Heijden (2017) and Savickas et al. (2009), workers need to manage several life and work transitions to obtain employment.

Such circumstances especially affect new entrants in the labour market, as evidenced by the average unemployment rate among young adults in the European Union (Eurostat, 2018a). For instance, in recent years, marked by the economic crisis and slow recovery (20072016), Italy has recorded a decrease in the percentage of new graduates who found employment within one year after graduation (AlmaLaurea, 2018; Eurostat, 2018b). Moreover, as they are still in the education-to-work transition phase, they are required to handle activities they have little familiarity with, besides being concerned about their future career and financial status. The transition phase could be experienced as difficult, leading new entrants in the labour market to experience anxiety and negative emotions, which

(C) Gerardo Petruzziello, Marco Giovanni Mariani, Rita Chiesa and Dina Guglielmi. Published by Emerald Publishing Limited. This article is published under the Creative Commons Attribution (CC BY 4.0) licence. Anyone may reproduce, distribute, translate and create derivative works of this article (for both commercial and non-commercial purposes), subject to full attribution to the original publication and authors. The full terms of this licence may be seen at: http://creativecommons.org/licences/by/4.0/ legalcode
Received 7 January 2019 Revised 19 July 2019 10 January 2020

3 March 2020

Accepted 29 March 2020

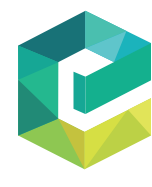

Personnel Review Vol. 50 No. 1,2021 pp. $225-243$ Emerald Publishing Limited DOI 10.1108/PR-01-2019-0009 
negatively impact job search strategies (Bonaccio et al., 2014), as well as physical and psychological health and well-being (Wanberg, 2012).

Seeking employment is considered a self-regulatory goal-directed process made up of multiple phases (Kanfer et al., 2001; Blau, 1994; Van Hooft et al., 2013) in which job seekers have to perform both preparatory behaviours (explore possible career goals, values, skills) to develop a job search goal and active job search behaviours (draw up a curriculum vitae, attend interviews with potential employers). In line with this, to maintain their behaviours and achieve their employment goals, new entrants looking for a job need to be equipped with self-regulatory resources, such as self-efficacy. Self-efficacy is considered to have a prominent role in the job search process and on its outcomes, according to various theoretical models (e.g. Saks, 2005; Lent and Brown, 2013; Van Hoye et al., 2015). Accordingly, research has extensively confirmed the benefits of self-efficacy on the job search. The feeling that they possess what it takes to succeed both encourages and sustains the endeavours of job seekers, leading to a higher effort in job search behaviours and success (Kanfer et al., 2001; Liu et al., 2014). Therefore, to explore how the job search success of new entrants is affected by selfefficacy, this study draws on the social cognitive career theory's career self-management model (CSM model, Lent and Brown, 2013), which postulates that self-efficacy has a pivotal role in many career management processes, including job search.

To move beyond typically used job search success criteria (Saks, 2006), the indicator of job search success proposed by this paper is an interviewer-rated hireability evaluation, assigned to graduated new entrants after a job interview simulation. This study proposes that hireability summarises the quality of action in some tasks preceding job interview (Barbulescu, 2015; Smart and DiMaria, 2018). According to Macan (2009), the interview remains a major technique that organisations use to make hiring decisions and, from the seeker's perspective, a job search task that occurs at the end of a seeking process (Barbulescu, 2015). Hence, the interview can provide information about the quality of an individual's job search and can be revealing about the outcome of the endeavour. Therefore, this paper investigates whether job search success is positively affected by job search self-efficacy beliefs, namely, the perceived ability to perform well in the various phases of a job search (Saks and Ashforth, 1999), using hireability evaluation - which reflects the likelihood of a candidate to be hired, as evaluated by the interviewer (Cuddy et al., 2015) - as a job search success criterion.

Another crucial goal of this study is to explore the moderating role of extraversion on the relationship between general self-efficacy, job search self-efficacy and job search success. In recent years, many authors have called for further research on the antecedents of job search self-efficacy (Van Hoye et al., 2019; Zikic and Saks, 2009). Accordingly, scholars found various predictors to job search self-efficacy, such as career planning and exploration (Saks et al., 2015), psychological capital (Pajic et al., 2018) and core-self evaluations Vîrga and Rusu, 2018). Moreover, even if general self-efficacy is considered an antecedent of specific forms of selfefficacy (Lusczynska et al., 2005), the relationship between general and specific forms of selfefficacy is far from being exhausted (Grether et al., 2018). Thus, we shall explore its relationship with job search self-efficacy and, subsequently, with job search success taking into consideration the role of extraversion in moderating this connection. Indeed, personality traits could be a crucial factor in job search activities (Kanfer et al., 2001), especially in those that prepare for a good performance during a job interview (Caldwell and Burger, 1998). Moreover, extraversion is a crucial factor in activities involving social interaction, such as a job interview (Huffcut et al., 2011; Tay et al., 2006). Hence, this paper investigates the moderating role of extraversion in boosting the effect of job search self-efficacy.

This study contributes in several ways to the existing literature. First, it suggests that hireability evaluation following the interview could be a criterion to assess job search success. This research tries to deploy an alternative success variable in place of criteria that have been typically used so far, such as job offers. A job offer may rely on several variables in addition to 
how a job seeker conducts his/her job search activities (Boswell et al., 2012). Therefore, using the simple count of the offers received may not adequately assess the success in the job search. Instead, in this research, it is proposed that hireability evaluation could be understood as a job search success variable because it condenses the performance of some previous job search activities (Barbulescu, 2015). Second, by exploring the antecedent role of general self-efficacy, this study contributes new knowledge about the relationship between general and specific forms of self-efficacy in the job search context. If confirmed the role of both job search and general self-efficacy might be revealing of the contribution of the study at a practical level. It is known that to be effective, career support interventions should improve seekers' resources such as self-efficacy, both specific and general (Eden and Aviram, 1993; Liu et al., 2014), by stimulating its sources (enactive mastering of a task, vicarious learning from role models, social and verbal persuasion and affective state; Bandura, 1997). Lastly, the moderating role of extraversion shows the alternative influence of personality traits on a job search, allowing practitioners to better adapt employment and job search interventions to individual differences. In fact, even personality traits can change, both as a result of normative maturation with age (Costa and McCrae, 2006) and of interventions aimed at achieving personality change by assigning participants goals and behaviours to pursue (Hudson and Fraley, 2015).

Overall, this study offers more in-depth insights into the positive role of personal resources in the context of new entrants' job search. Such information could be used in counselling and employment programmes to help new entrants to meet the demands of the labour market better.

\section{Theoretical background and hypotheses}

\section{Job search self-efficacy and job search success}

According to the social cognitive theory (Bandura, 1997), self-efficacy beliefs are considered a major self-regulatory resource that people can use to interact with the external environment effectively and achieve the desired goals. As self-efficacy refers to how people think about their ability to carry out activities and tasks, it is a major regulator of human behaviour. Indeed, it drives motivational, affective, cognitive and selection processes towards performance, thus producing the desired outcomes (Bandura, 1997).

The effects of self-efficacy on various psychological processes (Bandura, 2012) indicate that confidence in one's skills encourages people to engage in activities with higher goals and with higher levels of attention and effort to obtain greater satisfaction from the achievement of the expected results. Moreover, self-efficacy may enhance the ability to cope with difficulties, stressful situations or setbacks during the job search process. Hence, self-efficacy has received growing attention from scholars and practitioners in the field of career management (Kanfer, et al., 2001; Lent and Brown, 2013; Liu et al., 2014). Self-efficacious seekers could act more effectively in a self-regulatory job search process, which can be evaluated in terms of effort and intensity, the content of behaviours performed and persistence (Kanfer et al., 2001). Accordingly, self-efficacious job seekers may perform better in activities such as identifying employment goals and desired jobs, performing consistent behaviours (e.g. searching for information about a desired position, writing an effective curriculum vitae) and persisting in those behaviours even when they face setbacks or obstacles (e.g. stressful interview or the possibility of a refusal). Various theoretical models - Saks' model, which integrates antecedents and outcomes of job search behaviours (2005), and the CSM model (CSM model: Lent and Brown, 2013) - consider job search self-efficacy (henceforth JSSE), namely, one's beliefs about the ability to perform tasks and behaviours in the job search process successfully (Saks and Ashforth, 1999), a crucial factor that underpins job searching activities. CSM stems from the social cognitive career theory (SCCT; Lent et al., 1994), which was originally developed to predict the contents of career development, such as vocational or educational 
PR

50,1

\section{8}

choices. In trying to expand the SCCT, CSM offers an integrative theoretical framework to address the process underlying career development rather than trying to predict its contents. In other words, while SCCT explains how individuals figure out in which educational and occupational fields they are more likely to succeed, CSM focuses on how people implement critical actions to manage their career development behaviours, including those pertaining to job search, independently from their educational/occupational choices, thus complementing the SCCT. According to the CSM model, JSSE may predict job search outcomes both directly and indirectly by stimulating behavioural intentions and subsequent actions. Consistently, research shows that JSSE may foster the extent to which seekers engage in job search-related activities in terms of effort and intensity (Guan et al., 2013; Lin andFlores, 2013; Liu et al., 2014). Several studies have reported the impact of JSSE on job search achievements, using different criteria to assess job search success. For instance, Kanfer et al. (2001) found that JSSE is related to outcomes, such as search status and the number of job offers. Likewise, in a sample of graduates, Brown et al. (2006) observed that JSSE is a predictor of job search outcomes, such as the number of follow-up interviews and offers received.

Job search success is a conceptual umbrella, which includes several criteria that are used to indicate whether a search process has been successful and whether search behaviours were rightly performed (Saks, 2005). The majority of the cited studies employed job search success criteria, which, following the taxonomy introduced by Saks (2005), could be listed among those criteria called "job search outcomes". Achievements such as the number of job interviews and job offers have been used as immediate indicators of job search success (assessed during, or immediately after the conclusion of, a job search process; Saks, 2005). However, immediate criteria used so far might not assess job search success in the completest possible way. Boswell et al. (2012) argued that criteria such as job offers might be flawed indicators of job search success of new graduates, as the quantity of offers received might not meet requirements regarding the quality and functionality of job search behaviours. A job offer may not depend on how an applicant carries out the job search, but rather on many employer-related factors that might not be understood. Furthermore, job seekers may report job offers for positions/organisation they prefer less or may not report many job offers because they engage in a job search focused solely on positions they desire. For these reasons, job offers may not completely reveal a job search process as successful (Boswell et al., 2012).

Having said that, the criterion used in this study as the indicator of an effective job search process is the outcome of a job interview simulation, namely, interviewer evaluation of the candidate's hireability. Hireability evaluation could be defined as the rating given by the interviewer about the applicant's likelihood to be hired, based on the fit and relevance shown by the applicant with the ideal job and on the overall performance during the interview (Cable and Judge, 1997; Cuddy et al., 2015). This research attempts to complement the previously mentioned success criteria measurements by considering hireability as a job search outcome according to the taxonomy by Saks (2005). This research proposes that the evaluation of an applicant's hireability after a job interview may reflect the goodness or the functionality of some job search activities towards job search success. Hirebility may fill the lack of accuracy of flawed criteria like job offers. Differently from an offer resulting, for instance, from motives that sometimes are unknowable, hireability evaluation arouses from behaviours that a candidate may implement during the interview (Cuddy et al., 2015; Tews et al., 2018). Thus, it may be more revealing of the goodness of job search endeavour compared to a count of job offers. This criterion may exemplify the value of self-regulatory phases of job search (setting goals, preparing job search activities, initiating and maintaining seeking activities; Van Hooft et al., 2013). In her conceptualisation of the job search process, Barbulescu (2015) underlines that job interview is the final step of the behavioural cycle underlying the seeking sequence after the stages of selection of types of potential jobs and application - and it is critical in converting an application into an actual job offer. Therefore, the evaluation of hireability 
received after participating in a job interview might be revealing of the quality of previous job search endeavours because it is the "product" of those endeavours (Van Hooft et al., 2013). Hireability could, in fact, indicate whether the job search process led to success.

As a final stage of the job search process, candidates may benefit during a job interview from what they have done in the previous stages. In other words, performance in previous behaviours may be translated into the performance during a job interview. That is, job interview performance may be the outcome of a process in which candidates first sift through many job vacancies, seeking information about the options they prefer in terms of fit with their aspiration, interests or qualification. Subsequently, once they have decided which job they want to apply for, candidates invest energy into acquiring in-depth information about the position, to prepare a convincing application (e.g. a well-drafted curriculum vitae or cover letter). Candidates could then use the information obtained to review their experiences and attributes with regards job requirements, in a way that helps them to develop convincing arguments to deliver during the interview. Lastly, by capitalising on what they have done before, they could demonstrate during the interview that their profile is relevant to the particular position.

In line with this idea, Smart and DiMaria (2018) remarked on the importance of competent storytelling and presentation abilities to exemplify a candidate's mastery of a particular skill or situation or to convey the candidate's experience. Storytelling could contribute to effective impression management strategies, which are decisive for excellent performance (Huffcutt, 2011) and, subsequently, for favourable hireability evaluations (Bangerter et al., 2014). Smart and DiMaria (2018) and Van Hooft et al. (2013) remarked that preparatory behaviours performed in previous job search phases might nurture these presentation skills. Applicants may first perform activities such as reading job advertisements carefully, searching for information about the job, reviewing their own experiences and identifying their core skills and knowledge that match the job requirements (Smart and DiMaria, 2018). Applicants may then focus on positive and self-promoting thoughts and practise their verbal (answers to possible questions and preparing impacting stories to present themselves or to recall an experience or past behaviours) and non-verbal behaviours. In other words, they may, for instance, make proper utilisation of job-related information obtained by rehearsing answers and speeches to display, during the job interview, their fit with the position and the organisation.

Research shows that performance during the interview and its behavioural antecedents may impact, directly and indirectly, on hireability evaluations made by interviewers. For instance, Caldwell and Burger (1998) showed that interview success leading to job offers might result from pre-interview social job search activities, such as talking to someone who could provide job-related information. Cuddy et al. (2015), Ruben et al. (2015), Mast et al. (2011) found that candidates' hireability is significantly impacted by verbal (i.e. self-promotion strategies) and non-verbal behaviours implemented during the interview. Cable and Judge (1997) found that the likelihood that the interviewer would recommend a candidate for a job is influenced by the extent to which he/she can show fit with the job/organisation. Bangerter et al. (2014) and Tews et al. (2018) showed that the quality of answers given by interviewees might impact on interviewers' evaluation about the possibility to hire them. What is understandable is that the studies above-mentioned used hireability evaluation measure in relation with some interview behaviours (i.e. self-promotion and non-verbal behaviours) that could be facilitated and prepared by behaviours performed in previous stages of job search (like looking for job-related information, Caldwell et al., 1998; Smart and DiMaria, 2018).

With this in mind, this study proposes that if well-executed job search behaviours, enacted before the interview, impact on performance during the interview and if hireability evaluation depends on interview behaviours and performance, hireability may also reflect the goodness of job search behaviours. Therefore, hireability could be used to complete the immediate criteria (i.e. job search outcomes like job offers) adopted so far in establishing whether the job search has been successful. Accordingly, JSSE, which has been hypothesised as, and shown 
PR

50,1 to be, a significant predictor of job search and employment outcomes (Lent and Brown, 2013), may be an antecedent of this indicator of job search success.

\section{The relationship between general self-efficacy and job search self-efficacy}

Even if self-efficacy may be conceived as the belief in succeeding in a specific activity domain and its predictive power on behavioural outcomes is higher when related to narrower situations or task domains (Bandura, 1997), some scholars have conceptualised a general form of self-efficacy, namely, general self-efficacy (henceforth GSE). GSE is the perceived ability to perform across different situations (Lusczynska et al., 2005), and it stems from the number of success and failure events experienced during an individual's life span (Shelton, 1990). Despite obvious similarities with specific self-efficacy, GSE is considered a relatively stable belief that does not depend on situations and tasks. It is less susceptible to change, in that it differs from specific forms of self-efficacy (Eden, 1988). For instance, Smith et al. (2006) say that GSE is more robust to setbacks and negative feedback than specific-task selfefficacy in a learning context, thus confirming the distinction between these two concepts.

As argued by various authors, people may rely on their GSE based on different experiences in mastering new situations, until a domain-specific sense of efficacy is established (Grether et al., 2018; Schwarzer and Jerusalem, 1995). GSE may shape a more specific form of self-efficacy by helping individuals to perform effectively in an unfamiliar situation. In other words, GSE may encourage people to engage in new specific activities and, subsequently, the outcomes of their behaviours may inform their specific-task-related sense of efficacy (Shelton, 1990).

Many studies, such as the one conducted by Miyoshi (2012), report a top-down effect of GSE on specific-task-related self-efficacy. Chen et al. (2000) report that specific-task selfefficacy mediates the impact of GSE on performance. Grether et al. (2018) found that GSE might have a positive effect on various specific self-efficacy beliefs.

Scholars have only recently started exploring the relationship between GSE and JSSE. Virga and Risu (2018) say that JSSE could act as a mediator between core self-evaluations and outcomes, such as job search behaviours, mainly because of the GSE component of core selfevaluation. Moreover, Pajic et al. (2018) demonstrated that JSSE could be predicted by psychological capital, which encapsulates the sub-dimension of self-efficacy. However, to date, no studies have focused on the relationship between GSE and JSSE in new entrant populations.

Applying this knowledge to the job search domain of new entrants, it is arguable that because they are new to the job search process and activities, they may gain confidence from their general sense of efficacy generated by other situations/tasks they have successfully mastered. In line with this, Lent et al. (2016) supposed that new entrants who are not experienced in specific job search behaviours might inform their job search-related efficacy beliefs by generalising other experiences in their life, thus suggesting more in-depth investigations about the antecedents of JSSE in younger job seekers.

Drawing on the evidence and knowledge reported above, and focusing on the goal to further explore the role of self-efficacy in job search success, we could hypothesise that JSSE affects job search success in a sample of new entrants, as confirmed by interviewer evaluations of applicant hireability after a simulation of a job interview. Consistently with the CSM model (Lent and Brown, 2013), JSSE may have a direct and positive effect on job search outcomes. As the job search process could be an unknown situation to new entrants, it can also be hypothesised that their perceived ability in facing behaviours they are not familiar with stems from their general sense of efficacy. Thus:

H1. JSSE mediates the relationship between GSE and job search success such that GSE has a positive and indirect effect on job search success. 
Among other factors, personality traits may explain the performance of job seekers during a job search. Several authors (see, for example, Kanfer et al., 2001; Lent and Brown, 2013; Saks, 2005) have supposed that extraversion is a crucial factor for a job search because it may impact on JSSE and search behaviours and outcomes. As advanced by Costa and McRae (1992), extraverted people invest higher levels of vitality; they actively search for stimuli and effectively develop their social life and relations. In addition, extraverts may feel more comfortable in situations featuring social interactions, because they approach those interactions with higher levels of talkativeness, sociability and attention and sensitivity to others (McRae and Costa, 1999). For those reasons, extraversion might help people in social interaction, leading them to better results when the interaction is a means to achieve rewards (Wilmot et al., 2019).

Given these characteristics, it seems reasonable that extraversion supports individuals in the job search. Brown and Hirschi (2013) remarked that extraverts might benefit from the positive relations they tend to build (e.g. they may draw on their network to get information about job leads) and be more proactive in their search (e.g. actively searching for information about the desired position). Burger and Caldwell (2000) found that extraversion positively predicted involvement in social strategies applied to a job search (e.g. reliance on social networks). Moreover, Turban et al. (2009) showed that extraversion might have a positive impact on job search outcomes by improving self-regulation strategies (e.g. improve search and presentation skills). Baay et al. (2014) showed that, for extraverts, the probability of obtaining a job after graduation was higher, and the duration of unemployment was shorter. Such evidence suggests that extraversion may relate to the perceived ability to carry out job search and obtain expected results, namely, JSSE. Accordingly, Van Hoye et al. (2015) showed that extraversion is an antecedent of JSSE because extraverted job seekers may feel more capable of performing active and social job search behaviours.

This study addresses the role of extraversion because its methodology involves the utilisation of a simulation of a job interview. Firstly, as already said, extraversion is highly relevant in job search behaviours involving social interaction that could lead to valuable rewards, such as the job interview (Wilmot et al., 2019). Various authors (e.g. Burger and Caldwell, 2000; Kluemper et al., 2015; Tay et al., 2006) showed a positive effect of extraversion on performance during a job interview, because of higher sociability and talkativeness, which help candidates to use verbal and non-verbal communication better. Thus, they could better deliver their fit with the position and, subsequently, they could make a better impression (Caldwell and Burger, 1998).

Secondly, extraversion may also sustain job search behaviours that precede the job interview. Barbulescu (2015) argues that job search activities that anticipate, prepare for and lead to success in a job interview involve utilisation of social contacts. For instance, job seekers may search for contacts within the preferred organisations that could provide them with information about the company, its selection criteria and the job for which they want to apply, thus strengthening their learning about their desired position. In this way, they could become more knowledgeable about the job and better present themselves during the interview. Moreover, social contacts may also support the interview preparation stage, by helping job seekers to manage challenges encountered in the interview situation (e.g. giving a good presentation). Given that extraverts are more proactive, sociable and assertive, they may actively search for tips and information from social sources rather than rely only on nonsocial sources like companies' websites (Caldwell and Burger, 1998).

Unlike the mentioned study by Van Hoye et al. (2015), this research draws on the idea that extraversion may facilitate how job seekers spread their agency, namely JSSE, rather than predicting it. Hence, it may play a moderating role. The impact of extraversion on selfregulation strategies (Turban et al., 2009) may sustain and corroborate how job seekers use 
PR

50,1

232

their sense of efficacy about job search and have a boosting effect on their actions towards desired outcomes. For instance, the activity component of extraversion may encourage younger job seekers to canalise their agency towards social job search behaviours (e.g. search for "company insiders" to find valuable job-related information), rather than non-social activities, to better perform during an interview. Thus, following the goal to add knowledge about the relationship between JSSE and extraversion, it could be hypothesised that:

H2. The indirect effect of GSE on job search success through JSSE is moderated by the trait of extraversion in the JSSE-job search success path. The impact of JSSE on job search success will be higher for new entrants who are more extraverted.

The hypothesised relations among study variables are illustrated in Figure 1.

\section{Method \\ Sample and procedure}

Data were collected using a sample of new entrants recruited from among recent graduates from different degree courses of a leading Italian university.

Participants were people attending job search preparation activities (e.g. workshops, group activities) delivered by the career services of this university in the period 2016-2018. They were given the opportunity to participate in a job interview simulation held by a personnel selection expert. Participation in the job interview simulation was not mandatory. Those who took part in the interview simulation were asked, by e-mail, to prepare for it by thinking of an actual position they desired to implement consistent job search behaviours (e.g. gather data about the organisation they wanted to apply to, draw up a targeted curriculum vitae). Moreover, they were asked to bring their curriculum vitae along with them to the simulation. On the day of the simulation, participants were requested to give their informed consent to the procedure. A structured anonymous questionnaire was used to collect data about demographic variables, GSE, JSSE and extraversion.

The study guaranteed the anonymity and confidentiality of respondents. The questionnaire included a statement about personal data processing, following Italian and European privacy regulations (Decree no. 196/2003; EU Regulation no. 679/2016). Participants authorised the use of anonymous/collective data for scientific purposes. All of the personnel selection experts $(N=6)$ chosen to carry out the simulation had a multi-year experience in selection process both for companies (public and private sectors) and career services, and they were balanced by gender $(M=3 ; F=3)$. Moreover, they were trained and instructed to assess the behaviour and performance of participants and to use reliable criteria to evaluate their hireability, based on study goals and rationale (International Taskforce on Assessment Center Guidelines, 2015).

Each job interview simulation lasted 50 min per participant and was held by one interviewer. The simulation included a welcome phase $(5 \mathrm{~min})$, followed by the reading of the curriculum vitae by the interviewer $(5 \mathrm{~min})$. The actual interview simulation lasted ca $25-$ $30 \mathrm{~min}$. The interviewer had a 20-question interview schedule, including open-answer,

Figure 1. The hypothesised model

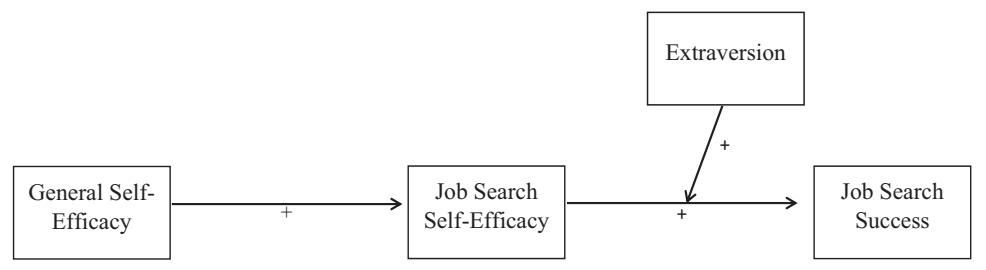


situational and behavioural questions (based on recommendations from Levashina et al., 2014). Questions included the following, "Tell me about yourself/please introduce yourself", "Tell me about a major problem you had during your experiences and how you solved it", "What skills do you consider to be the most important to this role?". After the simulated interview, the interviewer gave participants a brief feedback $(10 \mathrm{~min})$ on their performance, in terms of selfpromotion (candidates' ability to present their skills, knowledge, experience and motivation), knowledge of the role (the extent to which candidates are knowledgeable about main responsibilities and tasks required by the position), management of emotions (candidates' ability to control emotions felt during the interview and to remain calm) and adaptation to unexpected questions (the ability to answer tricky or uncommon questions from the interviewer). Participants could take notes using a structured sheet while they were receiving the feedback after the simulation.

Data about the variables involved in this study (GSE, JSSE, extraversion, age, gender) were collected before the simulation. The personnel selection expert gave a hireability evaluation after the simulation. Interviewers were asked to give a single hireability score considering the same criteria on which feedback was given (candidates' self-promotion, knowledge of the role, management of the emotions and unexpected questions) and considering to what extent participants seemed to fit with the position. For instance, they were instructed to base hireability on the extent to which participants would be able to show fit with the position (e.g. through self-promotion and knowledge of the role) and to answer the questions properly (e.g. by giving a proper example of past behaviours, problem-solving and adjustment to probing questions).

At the end of the data collection period, 177 participants had completed the whole questionnaire. The majority were female $(117 ; 66.01$ per cent). The mean age was $25.51(S D=3.11)$.

\section{Measures}

$J S S E$ was measured with eight adapted items $(\alpha=0.82)$ from the "Getting ready for your next job" scale developed by Wanberg et al. (2010). Respondents had to assess their level of confidence in effectively performing job search activities (e.g.: "During a job search, how confident do you feel about your skills in..." "... finding information about the companies before an interview" or "...presenting yourself well in an interview") on a five-point Likert scale (from $1=$ "[not confident] at all" to $5=$ "completely [confident]"). The original scale was part of a larger seven-factor questionnaire, which showed satisfactory fit indices.

$G S E$ was measured with eight items $(\alpha=0.90)$ from a scale developed by Jerusalem and Schwarzer (1992) and adapted in Italian by Mariani et al. (2017). Respondents had to assess how well the items described their general confidence in achieving goals and in overcoming challenges and obstacles (e.g. "I confidently and effectively complete different tasks"; "Even when faced with difficult situations, my performance is good") on a seven-point Likert scale (from $1=$ "it does not describe me at all" to 7 = "it describes me completely"). In the study by Mariani et al. (2017), a confirmatory factor analysis showed a good fit for this scale, and coefficient alpha was 0.72 .

Extraversion was measured with two items $(\alpha=0.77)$ from the ten-item personality inventory (TIPI) developed by Gosling et al. (2003) and validated in Italian by Chiorri et al. (2015). Respondents had to assess to what extent the traits reported by the items described them (e.g. "I am an..." "extroverted, enthusiastic [person]") on a seven-point Likert scale (from $1=$ "it does not describe me at all" to $7=$ "it describes me completely"). The Italian validation (Chiorri et al., 2015) recorded alpha values of 0.72, 0.64 and 0.66 .

Job search success was measured by the hireability evaluation of participants, made by the personnel selection expert who held the simulation, soon after the simulation and before the 

position he/she is applying for?" with a three-point response scale $(1=$ no; $2=$ maybe; $3=$ yes $)$. In using this measure, this study aligns with Van Hooft et al. (2013). According to these authors, an expert interviewer may assess how good job search behaviours have been according to expectations of principal parties in the labour market. Furthermore, in line with Barbulescu (2015) and Van Hooft et al. (2013), the job interview is the final step of the job search behavioural process and performance, at it could be influenced by previous activities.

Therefore, the hireability rating by an expert interviewer may also provide information about how good or, at least, functional pre-interview activities may be and whether those activities may eventually lead to success in the job search. Accordingly, to provide an appropriate hireability rating, interviewers were trained to inquire about participants' knowledge of the job or to ask questions to stimulate self-presentation or the recall of experience and behaviours. In this way, interviewers could have the possibility to test how good participants were at some job search behaviours, like searching for information to be knowledgeable about the ideal organisation/job and preparing their answers and stories to tell. The three-point response scale has been already used in other studies involving hireability evaluation (Cuddy et al., 2015) because it is an evaluation system commonly used in real job interview settings. To add some realism to the study and because in real conditions the interviewer/evaluator should give a judgement about hiring or not the candidate, the response scale for the hireability evaluation was re-coded in a dummy variable so that "no" and "maybe" answers were re-coded as 0 , and "yes" answers were re-coded as 1 .

Age and gender were also recorded to be included in the analysis as control variables, as they may impact on the job search process and activities (Kanfer, et al., 2001), JSSE (Wang et al., 2017) and on interviewers' rating about the applicants' hireability (Huffcutt et al., 2011).

\section{Data analysis}

IBM SPSS version 20 was used for the data analysis.

We used the analytical approach by Hayes (2012) to test the mediation (H1) and moderated mediation (H2) hypothesis. This procedure allows the testing of the indirect effect and conditional indirect effect, performing a bootstrap procedure that represents a more robust approach than the Sobel test (McKinnon et al., 2004). Hypothesis 1 was tested with Model 4 in the macro SPSS PROCESS (Hayes, 2012); Model 14 from the same macro was used for hypothesis 2 . Indirect effects and conditional indirect effects were estimated with a 95 per cent confidence interval. When the interval does not include zero, the effects are statistically significant at a 0.05 level. Age and gender were introduced to the analysis as control variables.

\section{Results}

Mean values, standard deviations, alpha values and correlations among the study variables are reported in Table 1 . As can be seen, GSE was positively related to JSSE, but not to job search success. Furthermore, JSSE was positively related to job search success. Extraversion was positively related to job search success, but not to JSSE. Among the two control variables (gender and age), only the gender was significantly related to job search success. Reliability values were assessed with Cronbach alpha. All values met the threshold of 0.70 , showing good reliability indices for the scales used (Nunnally and Bernstein, 1994).

\section{Testing the hypotheses}

Table 2 shows the estimates of path coefficients for the indirect effect analysis (H1), as well as the 95 per cent confidence intervals for path estimates. The results indicate that the direct 
effect of GSE on job search success was not significant, while GSE has a positive and indirect effect on job search success through JSSE $(B=0.18 ; S E=0.09 ; C I=0.04 ; 0.42)$. Thus, Hypothesis 1 was supported.

As shown in Table 3, the interaction effect of JSSE and extraversion on job search success was significant $(B=0.43$; $\mathrm{SE}=0.19 ; \mathrm{CI}=0.04 ; 0.82)$; specifically, a conditional effect analysis (Table 4) showed that the effect of JSSE on job search success was significant at high and medium levels of extraversion, but it was not significant at a low level of extraversion. Thus, Hypothesis 2 was confirmed. Figure 2 shows that when extraversion is higher, the impact of JSSE on job search success is stronger than the same effect found when extraversion is low.

\begin{tabular}{|c|c|c|c|c|c|c|c|c|}
\hline Variable & M & $\mathrm{SD}$ & 1 & 2 & 3 & 4 & 5 & \\
\hline 1. Gender ${ }^{\mathrm{a}}$ & - & - & - & & & & & \\
\hline 2. Age & 25.51 & 3.11 & 0.01 & - & & & & \\
\hline 3. GSE & 5.29 & 0.82 & 0.04 & 0.13 & - & & & \\
\hline 4. JSSE & 3.43 & 0.59 & -0.09 & 0.06 & $0.35 * *$ & - & & \\
\hline 5. EX & 3.97 & 1.49 & 0.15 & -0.05 & $0.25 * *$ & 0.05 & - & \\
\hline 6. JSS & 0.44 & 0.49 & $0.19 *$ & -0.14 & 0.06 & $0.16^{*}$ & $0.17^{*}$ & Descriptive statistics \\
\hline \multicolumn{8}{|c|}{$\begin{array}{l}\text { Note(s): } * p<0.05 ; * * p<0.01 ;{ }^{a} 1=\text { man, } 2=\text { woman; GSE, general self-efficacy; JSSE, job search self-efficacy; } \\
\text { EX, extraversion; JSS, job search success }\end{array}$} & $\begin{array}{l}\text { and correlations } \\
\text { among variables }\end{array}$ \\
\hline
\end{tabular}

\begin{tabular}{lcccc}
\hline & & & Job search success \\
Indirect effect & Direct effect & [LLCI; ULCI] \\
\hline Gender & B & $S E$ & CI (95\%) \\
Age & $0.96^{*}$ & 0.35 & \\
GSE & $-0.12^{*}$ & 0.06 & \\
JSSE & 0.04 & 0.21 & & \\
$G S E \rightarrow$ JSSE $\rightarrow$ JSS & $0.69^{*}$ & 0.05 & 0.18 & [0.04; 0.42]
\end{tabular}

Note(s): ${ }^{*} p<0.05 ;{ }^{a} 1=$ man, $2=$ woman; CI $(95 \%)=95 \%$ confidence interval using the bootstrap bias corrected method using 5,000 samples. GSE, general self-efficacy; JSSE, job search self-efficacy; JSS, job search success

Table 2.

Path coefficients for the indirect effect analysis

\begin{tabular}{lccrr}
\hline JSS & $B$ & $S E$ & LLCI & ULCI \\
\hline Gender ${ }^{\mathrm{a}}$ & $0.86^{*}$ & 0.36 & 0.16 & 1.56 \\
Age & $-0.13^{*}$ & 0.06 & -0.24 & -0.01 \\
GSE & -0.08 & 0.22 & -0.53 & 0.35 \\
$J S S E$ & -0.94 & 0.79 & -2.50 & 0.63 \\
$E X$ & -1.25 & 0.67 & -2.57 & 0.07 \\
$J S S E \times E X$ & $0.43^{*}$ & 0.19 & 0.04 & 0.82
\end{tabular}

Note(s): ${ }^{*} p<0.05 ;{ }^{a} 1=$ man, 2 = woman; GSE, general self-efficacy; JSSE, job search self-efficacy; EX, extraversion; JSS, job search success

Table 3. Interaction effect of JSSE and extraversion on job search success 
PR

50,1

\section{6}

Table 4.

Conditional effect analysis of JSSE effect on job search success at different levels of extraversion

\section{Discussion}

A major aim of this study was to investigate the role of self-efficacy in the job search process of new entrants and on job search success, taking into consideration both GSE and JSSE and testing the moderating role of extraversion. In line with the assumptions of the CSM model (Lent and Brown, 2013), the results confirm that JSSE may help individuals achieve better outcomes at the end of a job search process and align with past research on the JSSE-job search success relationship (Kanfer et al., 2001).

Unlike the cited studies, this research used, as an immediate indicator of success in job search, the hireability evaluation from an expert selection interviewer after a job interview simulation, drawing on the idea that a job interview exemplifies performance in some previous job search behaviours, and this is crucial to assess whether or not a job search process has been successful (Barbulescu, 2015). The results showed that JSSE has a positive effect on the evaluation of hireability. These results expand knowledge about job search success criteria assessed immediately after job search (Brasher and Chen, 1999; Saks, 2005). Moreover, as it has been argued that hireability evaluation reflects the goodness or, at least, the functionality of some job search activities before an interview, this measure could be used by scholars and practitioners to assess the success of a job search process, also addressing behaviours that could lead to success in the interview situations.

The positive effect of JSSE on job search success is consistent with previous studies (Brown et al., 2006; Kanfer et al., 2001) and confirms that believing in having what it takes to succeed may lead to achieving the expected results. What this study adds to the research is evidence of the positive relationship between GSE and JSSE. The findings confirm that by drawing on their general sense of efficacy, people may foster specific forms of self-efficacy related to narrower activity domains (Shelton, 1990; Chen et al., 2001) and use them to achieve

\begin{tabular}{lccc}
\hline Condition & B & SE & Boot 95\% CI \\
\hline Low extraversion level (-1 SD) & 0.03 & 0.11 & {$[-0.15 ; 0.33]$} \\
Mean extraversion level & 0.19 & 0.10 & {$[0.04 ; 0.43]$} \\
High extraversion level (+1 SD) & 0.36 & 0.17 & {$[0.12 ; 0.79]$} \\
\hline
\end{tabular}

Figure 2.

Interactive effects of JSSE and extraversion on job search success

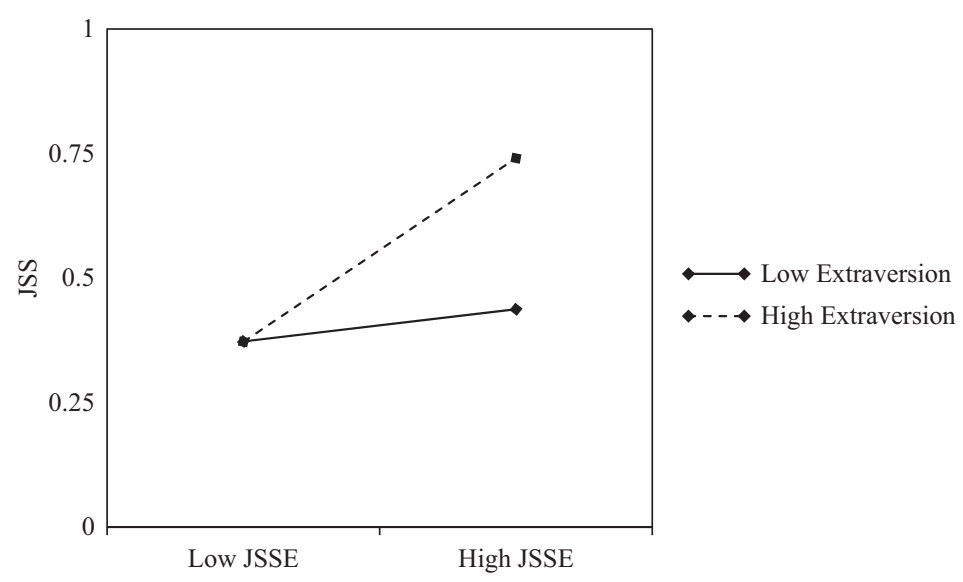

Note(s): JSSE, Job search self-efficacy; SS, Job search success 
the expected results, including those related to job search activities. Furthermore, the positive and indirect effect of GSE on job search success confirms that GSE may help individuals in unfamiliar domains to establish more specific efficacy beliefs, as shown by Grether et al. (2018) and by Miyoshi (2012). This result expands knowledge about factors from which JSSE stems in new entrants. Theoretically, this finding could lead to an extension of the CSM model, as GSE could be included as an antecedent of JSSE when the model is used to study the job search process in younger populations.

However, GSE affects job search success only through JSSE. These results are consistent with the social cognitive theory's assumption that self-efficacy beliefs are more robust predictors of human function and behavioural outcomes when referred to specific activity domains because they are competency based and better match the outcome criteria assessed at a high level of specificity (Bandura, 1997; Chen et al., 2001). These results confirm that GSE and more specific forms of self-efficacy (such as JSSE, in this case) are different constructs.

Finally, the $\mathrm{H} 2$ test revealed that extraversion might intensify the effect of JSSE on job search success, which stands as a major contribution of this study. This result is consistent with the idea that besides a predictive role regarding JSSE (Van Hoye et al., 2015), a moderating effect on the JSSE-job search outcome relationship is also possible. The weak and insignificant correlation between extraversion and JSSE and the interaction effect found between these two variables underpin the idea that extraverts could better exploit their selfefficacy about job search in a social-oriented fashion. These results could be explained by the fact that extraversion might sustain individuals during an interview, for which social skills are crucial. Moreover, extraversion could also amplify the effect of perceived ability in performing job search behaviours - such as searching for job-related information - leading to a good outcome after an interview (Caldwell and Burger, 1998). However, more research is needed to clarify the relationship between JSSE and personality traits by measuring these behaviours.

\section{Limitations and implications for research}

This study has various limitations. First, job search success assessed through hireability evaluation of candidates after a job interview may complement criteria used to date, but some characteristics of the study may harm the accuracy of this measure, which should be tested through further research. As many studies have argued (Huffcut et al., 2011), the evaluation made by an interviewer could be influenced by various factors, such as the interviewer's personality traits, information processing skills and interview structure (Levashina et al., 2014). Future research could assess job search success using hireability evaluation and controlling for disturbing variables. Moreover, the participants were involved in a simulated employment interview within the university career services, thus reducing the generalisability of the results. Thus, this study could be replicated in an actual selection context and with different groups of job seekers to examine the validity of the job search success criteria used.

Furthermore, even though this study advances the idea that the criteria used for measuring success reflect performance in previous activities, those activities were not included or measured. Further research could address the job search behaviours that have been mentioned as fostering a good performance during an interview (e.g. carefully reading job advertisements or searching for information about the position) and, subsequently, a favourable hireability evaluation as a criterion for job search success.

As Saks says (2005), "job search success" refers to a group of immediate and distal criteria. Immediate success criteria may have an impact on distal criteria (such as employment quality). Measures of employment quality may reveal more about how well new entrants 
PR

50,1

\section{8}

behave in seeking a job that better suits their interests and aspirations. Hence, this study could be replicated to assess the success of a job search by integrating the hireability evaluation with some measurements of the quality of work experiences, once employment has been obtained. Expanding this research to actual pre-interview job search tasks and behaviours could also allow to address better the moderating role of extraversion that has been explored in this study.

Second, the relationship between GSE and JSSE was investigated with cross-sectional data, thus weakening conclusions about the changes caused by GSE on JSSE over time. Future studies could investigate the top-down effect of GSE on JSSE by collecting data at different points in time and assessing JSSE after job search behaviours have been performed, as Greather et al. (2018) did in addressing other domain-specific self-efficacy beliefs. Furthermore, as shown by Miyoshi (2012), there could be mutual relations between GSE and specific self-efficacy. When specific self-efficacy is established, the sense of confidence and control achieved may fuel broader and general trust in one's abilities in a bottom-up fashion. Future studies could investigate the mutual relationship between GSE and JSSE.

\section{Practical implications}

Despite its limitations and besides its research implications, this study also suggests some practical implications. Consistent with our findings, job search services could develop training aimed at increasing both GSE and JSSE, drawing on the sources of self-efficacy. Guidance and job search practitioners could help new entrants to generalise their life experiences to stimulate GSE - which is somewhat malleable, despite being considered a stable trait-like characteristic (Eden and Aviram, 1993) - and thus encourage them to engage in early job searches. Moreover, as self-efficacy is a competency-based resource, interventions should be studied to provide new entrants with job search skills they can rely on to build their JSSE. For instance, as widely shown empirically (Eden and Aviram, 1993; Latham and Budworth, 2006; Liu et al., 2014), they could be supported by practising job search skills with exercises, such as role-plays (enactive mastering), by watching the successful performance of search activities (vicarious learning) and by using either verbal self-guidance or performance feedback (verbal and social persuasion).

Turning to the role of extraversion, in line with the evidence by Hudson and Fraley (2015), employment programmes could encourage extraversion-related goals and job search behaviours in less extraverted seekers (e.g. proactivity and social behaviours by searching for someone belonging to the preferred organisation to obtain job-related information or by conducting a mock interview to improve interaction capabilities; Liu et al., 2014) so that they can improve their performance throughout the job search and job interview.

In conclusion, this study analyses the role of psychological resources as human functioning regulators towards desired outcomes in the job search context, and it opens new paths of research and practice. Self-efficacy has been confirmed as a crucial personal resource that can help new entrants in their early job search attempts.

As this study involved recent graduates, the findings encourage universities to support their students and graduates in developing resources to better enter and fit into the contemporary labour market.

\section{References}

AlmaLaurea (2018), "XX Indagine condizione occupazionale dei laureati. Sintesi del rapporto 2018", available at: http://www.almalaurea.it/universita/occupazione/occupazione16 (accessed 10 December 2018). 
Baay, P.E., Van Aken, M.A., De Ridder, D.T. and Van der Lippe, T. (2014), "Understanding the role of social capital in adolescents' Big Five personality effects on school-to-work transitions", Journal of Adolescence, Vol. 37 No. 5, pp. 739-748.

Bandura, A. (1997), Self-efficacy: The Exercise of Control, W H Freeman/Times Books/ Henry Holt, New York, NY.

Bandura, A. (2012), "On the functional properties of perceived self-efficacy revisited", Journal of Management, Vol. 38 No. 1, pp. 9-44.

Bangerter, A., Corvalan, P. and Cavin, C. (2014), "Storytelling in the selection interview? How applicants respond to past behavior questions", Journal of Business and Psychology, Vol. 29 No. 4, pp. 593-604.

Barbulescu, R. (2015), "The strength of many kinds of ties: unpacking the role of social contacts across stages of the job search process", Organization Science, Vol. 26 No. 4, pp. 1040-1058.

Blau, G. (1994), "Testing a two-dimensional measure of job search behaviour", Organizational Behavior and Human Decision Processes, Vol. 59 No. 2, pp. 288-312.

Bonaccio, S., Gauvin, N. and Reeve, C.L. (2014), "The experience of emotions during the job search and choice process among novice job seekers", Journal of Career Development, Vol. 41 No. 3, pp. 237-257.

Boswell, W.R., Zimmerman, R.D. and Swider, B.W. (2012), "Employee job search: toward an understanding of search context and search objectives", Journal of Management, Vol. 38 No. 1, pp. 129-163.

Brasher, E.E. and Chen, P.Y. (1999), "Evaluation of success criteria in job search: a process perspective", Journal of Occupational and Organizational Psychology, Vol. 72 No. 1, pp. 57-70.

Brown, S.D. and Hirschi, A. (2013), "Personality, career development, and occupational attainment", in Brown, S.D. and Lent, R.W. (Eds), Career Development and Counseling: Putting Theory and Research to Work, 2nd ed., Wiley, New York, NY, pp. 299-328.

Brown, D.J., Cober, R.T., Kane, K., Levy, P.E. and Shalhoop, J. (2006), "Proactive personality and the successful job search: a field investigation with college graduates", Journal of Applied Psychology, Vol. 91 No. 3, pp. 717-726.

Burger, J.M. and Caldwell, D.F. (2000), "Personality, social activities, job-search behavior and interview success: distinguishing between PANAS trait positive affect and NEO extraversion", Motivation and Emotion, Vol. 24 No. 1, pp. 51-62.

Cable, D.M. and Judge, T.A. (1997), "Interviewers' perceptions of person-organization fit and organizational selection decisions", Journal of Applied Psychology, Vol. 82 No. 4, pp. 546-561.

Caldwell, D.F. and Burger, J.M. (1998), "Personality characteristics of job applicants and success in screening interviews", Personnel Psychology, Vol. 51 No. 1, pp. 119-136.

Chen, G., Gully, S.M., Whiteman, J.A. and Kilcullen, R.N. (2000), "Examination of relationships among trait-like individual differences, state-like individual differences, and learning performance", Journal of Applied Psychology, Vol. 85 No. 6, pp. 835-847.

Chen, G., Gully, S.M. and Eden, D. (2001), "Validation of a new general self-efficacy scale", Organizational Research Methods, Vol. 4 No. 1, pp. 62-83.

Chiorri, C., Bracco, F., Piccinno, T., Modafferi, C. and Battini, V. (2015), "Psychometric properties of a revised version of the ten item personality inventory", European Journal of Psychological Assessment, Vol. 31, pp. 109-119.

Costa, P.T. and McCrae, R.R. (2006), "Age changes in personality and their origins: comment on Roberts, Walton, and Viechtbauer”, Psychological Bulletin, Vol. 132 No. 1, pp. 26-28.

Costa, P.T. Jr and McRae, R.R. (1992), Revised NEO Personality Inventory (NEO-PI-R) and NEO FiveFactor Inventory (NEO-FFI) Professional Manual, Psychological Assessment Resources, Odessa, Florida.

Cuddy, A.J., Wilmuth, C.A., Yap, A.J. and Carney, D.R. (2015), "Preparatory power posing affects nonverbal presence and job interview performance", Journal of Applied Psychology, Vol. 100 No. 4, pp. 1286-1295. 
PR

50,1

De Vos, A. and Van der Heijden, B.I. (2017), "Current thinking on contemporary careers: the key roles of sustainable HRM and sustainability of careers", Current opinion in environmental sustainability, Vol. 28, pp. 41-50.

Eden, D. (1988), "Pygmalion, goal setting, and expectancy: compatible ways to boost productivity", Academy of Management Review, Vol. 13 No. 4, pp. 639-652.

Eden, D. and Aviram, A. (1993), "Self-efficacy training to speed reemployment: helping people to help themselves", Journal of Applied Psychology, Vol. 78 No. 3, pp. 352-360.

Eurostat (2018a), "Unemployment statistics”, available at: https:/ec.europa.eu/eurostat/statistics-explained/ index.php/Unemployment_statistics\#Youth_unemployment (accessed 10 December 2018).

Eurostat (2018b), "Employment rates of recent graduates", available at: https://ec.europa.eu/eurostat/ statistics-explained/index.php/Employment_rates_of_recent_graduates\#Employment_rates_ of_recent_graduates (accessed 10 December 2018).

Gosling, S.D., Rentfrow, P.J. and Swann, W.B. Jr (2003), "A very brief measure of the Big-Five personality domains", Journal of Research in Personality, Vol. 37 No. 6, pp. 504-528.

Grether, T., Sowislo, J.F. and Wiese, B.S. (2018), “Top-down or bottom-up? Prospective relations between general and domain-specific self-efficacy beliefs during a work-family transition”, Personality and Individual Differences, Vol. 121, pp. 131-139.

Guan, Y., Deng, H., Sun, J., Wang, Y., Cai, Z., Ye, L. and Li, Y. (2013), "Career adaptability, job search self-efficacy and outcomes: a three-wave investigation among Chinese university graduates", Journal of Vocational Behavior, Vol. 93 No. 3, pp. 561-570.

Hayes, A.F. (2012), "PROCESS: a versatile computational tool for observed variable mediation, moderation, and conditional process modeling [White paper]", available at: http://www.afhayes. com/public/process2012.pdf.

Hudson, N.W. and Fraley, R.C. (2015), "Volitional personality trait change: can people choose to change their personality traits?", Journal of Personality and Social Psychology, Vol. 109 No. 3, pp. 490-507.

Huffcutt, A.I. (2011), "An empirical review of the employment interview construct literature", International Journal of Selection and Assessment, Vol. 19 No. 1, pp. 62-81.

Huffcutt, A.I., Van Iddekinge, C.H. and Roth, P.L. (2011), "Understanding applicant behavior in employment interviews: a theoretical model of interviewee performance", Human Resource Management Review, Vol. 21 No. 4, pp. 353-367.

International Taskforce on Assessment Center Guidelines (2015), "Guidelines and ethical considerations for assessment center operations", Journal of Management, Vol. 41 No. 4, pp. 1244-1273.

Jerusalem, M. and Schwarzer, R. (1992), "Self-efficacy as a resource factor in stress appraisal processes", in Schwarzer, R. (Ed.), Self-efficacy: Thought Control of Action, Hemisphere, Washington, DC, pp. 195-213.

Kanfer, R., Wanberg, C.R. and Kantrowitz, T.M. (2001), "Job search and employment: a personalitymotivational analysis and meta-analytic review", Journal of Applied Psychology, Vol. 86 No. 5, pp. 837-855.

Kluemper, D.H., McLarty, B.D., Bishop, T.R. and Sen, A. (2015), "Interviewee selection test and evaluator assessments of general mental ability, emotional intelligence and extraversion: relationships with structured behavioral and situational interview performance", Journal of Business and Psychology, Vol. 30 No. 3, pp. 543-563.

Latham, G.P. and Budworth, M.H. (2006), "The effect of training in verbal self-guidance on the selfefficacy and performance of Native North Americans in the selection interview", Journal of Vocational Behavior, Vol. 68 No. 3, pp. 516-523.

Lent, R.W. and Brown, S.D. (2013), "Social cognitive model of career self-management: toward a unifying view of adaptive career behavior across the life span", Journal of Counseling Psychology, Vol. 60 No. 4, pp. 557-568. 
Lent, R.W., Brown, S.D. and Hackett, G. (1994), "Toward a unifying social cognitive theory of career and academic interest, choice, and performance", Journal of Vocational Behavior, Vol. 45 No. 1, pp. 79-122.

Lent, R.W., Ezeofor, I., Morrison, M.A., Penn, L.T. and Ireland, G.W. (2016), "Applying the social cognitive model of career self-management to career exploration and decision-making", Journal of Vocational Behavior, Vol. 93, pp. 47-57.

Levashina, J., Hartwell, C.J., Morgeson, F.P. and Campion, M.A. (2014), “The structured employment interview: narrative and quantitative review of the research literature", Personnel Psychology, Vol. 67 No. 1, pp. 241-293.

Lin, Y.J. and Flores, L.Y. (2013), "Job search self-efficacy of East Asian international graduate students", Journal of Career Development, Vol. 40 No. 3, pp. 186-202.

Liu, S., Huang, J.L. and Wang, M. (2014), "Effectiveness of job search interventions: a meta-analytic review”, Psychological Bulletin, Vol. 140 No. 4, pp. 1009-1041.

Liu, S., Wang, M., Liao, H. and Shi, J. (2014), "Self-regulation during job search: the opposing effects of employment self-efficacy and job search behavior self-efficacy", Journal of Applied Psychology, Vol. 99 No. 6, pp. 1159-1172.

Luszczynska, A., Scholz, U. and Schwarzer, R. (2005), "The general self-efficacy scale: multicultural validation studies", The Journal of psychology, Vol. 139 No. 5, pp. 439-457.

Macan, T. (2009), "The employment interview: a review of current studies and directions for future research", Human Resource Management Review, Vol. 19 No. 3, pp. 203-218.

Mariani, M.G., Chiesa, R. and Gill, H. (2017), "Self-efficacy and justice perceptions in personnel selection: a moderated mediation model", International Journal of Selection and Assessment, Vol. 25 No. 2, pp. 203-211.

Mast, M.S., Frauendorfer, D. and Popovic, L. (2011), "Self-promoting and modest job applicants in different cultures", Journal of Personnel Psychology, Vol. 10 No. 2, pp. 70-77.

McCrae, R.R. and Costa, P.T. Jr (1999) "A five-factor theory of personality”, in Pervin, L.A. and John, O.P. (Eds), Handbook of Personality: Theory and Research, 2nd ed., Guilford, New York, pp. 139-153.

McKinnon, D.P., Lockwood, C.M. and Williams, J. (2004), "Confidence limits for the indirect effect: distribution of the product and resampling methods", Multivariate Behavioral Research, Vol. 39 No. 1, pp. 99-128.

Miyoshi, A. (2012), "The stability and causal effects of task-specific and generalized self-efficacy in college", Japanese Psychological Research, Vol. 54 No. 2, pp. 150-158.

Nunnally, J.C. and Bernstein, I.H. (1994), Psychometric Theory (McGraw-Hill Series in Psychology), McGraw-Hill, New York, Vol. 3.

Pajic, S., Ulceluse, M., Kismihók, G., Mol, S.T. and den Hartog, D.N. (2018), "Antecedents of job search self-efficacy of Syrian refugees in Greece and The Netherlands", Journal of Vocational Behavior, Vol. 105, pp. 159-172.

Ruben, M.A., Hall, J.A. and Schmid Mast, M. (2015), "Smiling in a job interview: when less is more", The Journal of Social Psychology, Vol. 155 No. 2, pp. 107-126.

Saks, A.M. (2005), "Job Search Success: a review and integration of the predictors, behaviors, and outcomes", in Brown, S.D. (Ed.), Career Development and Counseling: Putting Theory and Research to Work, John Wiley, Hoboken, NJ, pp. 155-179.

Saks, A.M. (2006), "Multiple predictors and criteria of job search success", Journal of Vocational Behavior, Vol. 68 No. 3, pp. 400-415.

Saks, A.M. and Ashforth, B.E. (1999), "Effects of individual differences and job search behaviors on the employment status of recent university graduates", Journal of Vocational Behavior, Vol. 54 No. 2, pp. 335-349.

Saks, A.M., Zikic, J. and Koen, J. (2015), "Job search self-efficacy: reconceptualizing the construct and its measurement", Journal of Vocational Behavior, Vol. 86, pp. 104-114. 
PR

50,1

Savickas, M.L., Nota, L., Rossier, J., Dauwalder, J.P., Duarte, M.E., Guichard, J. and Van Vianen, A.E. (2009), "Life designing: a paradigm for career construction in the 21st century", Journal of Vocational Behavior, Vol. 75 No. 3, pp. 239-250.

Schwarzer, R. and Jerusalem, M. (1995), "Generalized self-efficacy scale”, in Weinman, J., Wright, S. and Johnston, M. (Eds), Measures in Health Psychology: A User's Portfolio. Causal and Control Beliefs, Nfer-Nelson, Windsor, pp. 35-37.

Shelton, S.H. (1990), "Developing the construct of general self-efficacy", Psychological Reports, Vol. 66 No. 3, pp. 987-994.

Smart, K.L. and DiMaria, J. (2018), "Using storytelling as a job-search strategy", Business and Professional Communication Quarterly, Vol. 81 No. 2, pp. 185-198.

Smith, S.A., Kass, S.J., Rotunda, R.J. and Schneider, S.K. (2006), "If at first you don't succeed: effects of failure on general and task-specific self-efficacy and performance", North American Journal of Psychology, Vol. 8 No. 1, pp. 171-182.

Tay, C., Ang, S. and Van Dyne, L. (2006), "Personality, biographical characteristics, and job interview success: a longitudinal study of the mediating effects of interviewing self-efficacy and the moderating effects of internal locus of causality", Journal of Applied Psychology, Vol. 91 No. 2, pp. 446-454.

Tews, M.J., Stafford, K. and Michel, J.W. (2018), "Interview etiquette and hiring outcomes", International Journal of Selection and Assessment, Vol. 26 Nos 2-4, pp. 164-175.

Turban, D.B., Stevens, C.K. and Lee, F.K. (2009), "Effects of conscientiousness and extraversion on new labor market entrants' job search: the mediating role of metacognitive activities and positive emotions", Personnel Psychology, Vol. 62 No. 3, pp. 553-573.

Van Hooft, E.A., Wanberg, C.R. and Van Hoye, G. (2013), "Moving beyond job search quantity: towards a conceptualization and self-regulatory framework of job search quality", Organizational Psychology Review, Vol. 3 No. 1, pp. 3-40.

Van Hoye, G., Saks, A.M., Lievens, F. and Weijters, B. (2015), "Development and test of an integrative model of job search behavior", European Journal of Work and Organizational Psychology, Vol. 24 No. 4, pp. 544-559.

Van Hoye, G., Van Hooft, E.A., Stremersch, J. and Lievens, F. (2019), "Specific job search self-efficacy beliefs and behaviors of unemployed ethnic minority women", International Journal of Selection and Assessment, Vol. 27, pp. 9-20.

Vîrga, D. and Rusu, A. (2018), "Core self-evaluations, job search behaviour and health complaints: the mediating role of job search self-efficacy”, Career Development International, Vol. 23 No. 3, pp. 261-273.

Wanberg, C.R. (2012), "The individual experience of unemployment”, Annual Review of Psychology, Vol. 63, pp. 369-396.

Wanberg, C.R., Zhang, Z. and Diehn, E.W. (2010), "Development of the "getting ready for your next job" inventory for unemployed individuals", Personnel Psychology, Vol. 63 No. 2, pp. 439-478.

Wang, L., Xu, H., Zhang, X. and Fang, P. (2017), "The relationship between emotion regulation strategies and job search behavior among fourth-year university students", Journal of Adolescence, Vol. 59, pp. 139-147.

Wilmot, M.P., Wanberg, C.R., Kammeyer-Mueller, J.D. and Ones, D.S. (2019), "Extraversion advantages at work: a quantitative review and synthesis of the meta-analytic evidence", Journal of Applied Psychology, Vol. 104 No. 12, pp. 1447-1470.

Zikic, J. and Saks, A.M. (2009), "Job search and social cognitive theory: the role of career-relevant activities", Journal of Vocational Behavior, Vol. 74 No. 1, pp. 117-127.

\section{Further reading}

Legislative Decree DL-196/2003, "Personal data protection code", available at: http://www.camera.it/ parlam/leggi/deleghe/03196dl.htm (accessed 10 December 2018). 
European Union (2016), "Regolamento (UE) 2016/679", available at: https://eur-lex.europa.eu/legalcontent/IT/TXT/PDF/?uri=CELEX:32016R0679\&from=IT (accessed 10 December 2018).

\section{Corresponding author}

Gerardo Petruzziello can be contacted at: gerardo.petruzziell2@unibo.it 